\title{
Conception and Development of Microfabricated Elements for Microfluidic Analytical Devices ${ }^{+}$
}

\author{
Irene Lara-Ibeas ${ }^{1, *}$, Christina Andrikopoulou ${ }^{1}$, Vincent Person ${ }^{2}$, Alireza Sharifi ${ }^{2,3}$, \\ Dimitris Valougeorgis ${ }^{3}$, Stéphane Colin ${ }^{4}$ and Stéphane Le Calvé ${ }^{1,2}$ \\ 1 Institute of Chemistry and Processes for Energy, Environment and Health (ICPEES), \\ University of Strasbourg, 67087 Strasbourg, France; candrikopoulou@unistra.fr (C.A.); \\ slecalve@unistra.fr (S.L.C.) \\ 2 In'Air Solutions, 25 Rue Becquerel-Bâtiment 71A, 67087 Strasbourg, France; \\ vperson@inairsolutions.fr (V.P.); sharifi@uth.gr (A.S.) \\ 3 School of Engineering, Department of Mechanical Engineering, University of Thessaly, 38334 Volos, \\ Greece; diva@mie.uth.gr \\ 4 INSA Toulouse, Institute Clément Ader, 31400 Toulouse, France; colin@insa-toulouse.fr \\ * Correspondence: ilaraibeas@unistra.fr \\ + Presented at the 5th International Symposium on Sensor Science (I3S 2017), Barcelona, Spain, \\ 27-29 September 2017.
}

Published: 4 December 2017

Portability and low energy consumption are of a great importance for on-site real-time monitoring of indoor air quality. Therefore, this work is focused on the miniaturization of the elements which are the bulkiest and require the highest energy supply in analytical devices. More specifically, micro-fabrication techniques were deployed so that a pre-concentrator and a gas chromatography micro-column with integrated heaters and temperature sensors were developed on silicon wafers of small dimensions of $20 \mathrm{~mm} \times 12 \mathrm{~mm}$ and $50 \mathrm{~mm} \times 50 \mathrm{~mm}$, respectively.

Heating elements and sensors were fabricated by thermal evaporation of titaniumand gold. In the GC micro-column, four resistances of $82 \Omega$ allow a temperature increase up to $200{ }^{\circ} \mathrm{C}$ in $150 \mathrm{~s}$ whereas two $430 \Omega$ resistances function as sensors. In the case of the pre-concentrator, three different designs containing heaters of $50-446 \Omega$ and sensors of 117-555 $\Omega$ were proposed in order to investigate the most appropriate configuration to achieve a temperature increase up to $250{ }^{\circ} \mathrm{C}$ in $10 \mathrm{~s}$.

Furthermore, a study of wet etching kinetics of $\mathrm{Si}<100>$ with $\mathrm{KOH}(40 \%)$ was performed to evaluate its suitability for the fabrication of micro-channels. Silicon etching rates were determined to be between 14.7 and $63.1 \mu \mathrm{m} / \mathrm{h}$ at different temperatures from $50-80{ }^{\circ} \mathrm{C}$. Afterwards, three GC micro-columns of 1, 2 and $3 \mathrm{~m}$ in length containing 106 and $146 \mu \mathrm{m}$ deep microchannels were etched using $\mathrm{KOH}(40 \%)$ at $70{ }^{\circ} \mathrm{C}$, thus demonstrating that wet etching is an alternative and cheaper technique to fabricate micro-columns.

Acknowledgments: This work was supported through the European project ELCOD. The ELCOD project was implemented as a part of the INTERREG V Oberrhein/Rhin Supérieur program and was supported by the European Regional Development Fund (ERDF) and the co-financed project partners Region Grand Est in France and the countries of Baden-Württemberg and Rhineland-Palatinate. This project has also received funding from the Clean Sky 2 Joint Undertaking under the European Union's Horizon 2020 research and innovation programme under grant agreement No 687014. Microfabrication techniques during this work were deployed in the nanotechnology platform STnano (IPCMS - CNRS, University of Strasbourg).

(C) 2017 by the authors. Licensee MDPI, Basel, Switzerland. This article is an open access article distributed under the terms and conditions of the Creative Commons Attribution (CC BY) license (http://creativecommons.org/licenses/by/4.0/). 